\title{
Material type influences the abundance but not richness of colonising organisms on marine structures
}

\section{Dodds, KC}

http://hdl.handle.net/10026.1/18701

\begin{abstract}
10.1016/j.jenvman.2022.114549
Journal of Environmental Management

Elsevier BV
\end{abstract}

All content in PEARL is protected by copyright law. Author manuscripts are made available in accordance with publisher policies. Please cite only the published version using the details provided on the item record or document. In the absence of an open licence (e.g. Creative Commons), permissions for further reuse of content should be sought from the publisher or author. 


\title{
Material type influences the abundance but not richness of colonising organisms on marine structures
}

\author{
Kate C. Dodds ${ }^{a, *, 1}$, Nina Schaefer ${ }^{\text {b,c, }}{ }^{\text {, Melanie J. Bishop }}{ }^{\text {a }}$, Shinichi Nakagawa ${ }^{\mathrm{d}}$, \\ Paul R. Brooks ${ }^{\mathrm{e}}$, Antony M. Knights ${ }^{\mathrm{f}}$, Elisabeth M.A. Strain ${ }^{\mathrm{g}, \mathrm{h}}$ \\ ${ }^{a}$ Department of Biological Sciences, Macquarie University, North Ryde, New South Wales, 2109, Australia \\ ${ }^{\mathrm{b}}$ Sydney Institute of Marine Science, Building 19 Chowder Bay Road, Mosman, New South Wales, 2088, Australia \\ ${ }^{c}$ Department of Earth and Environmental Sciences, Macquarie University, North Ryde, New South Wales, 2109, Australia \\ d School of Biological, Earth and Environmental Sciences, University of New South Wales, 2052, Australia \\ ${ }^{\mathrm{e}}$ Earth Institute \& School of Biology and Environmental Sciences, University College Dublin, Ireland \\ ${ }^{\mathrm{f}}$ School of Biological and Marine Sciences, University of Plymouth, Drake Circus, Plymouth, PL4 8AA, United Kingdom \\ ${ }^{\mathrm{g}}$ Institute for Marine and Antarctic Studies, University of Tasmania, 7001, Australia \\ ${ }^{\mathrm{h}}$ Centre for Marine Socioecology, University of Tasmania, Hobart, Tasmania, 7053, Australia
}

\section{A R T I C L E I N F O}

\section{Keywords:}

Artificial structures

Colonisation

Eco-engineering

Marine construction

Meta-analysis

Multifunctional design

\begin{abstract}
A B S T R A C T
Urbanisation of coastal areas and growth in the blue economy drive the proliferation of artificial structures in marine environments. These structures support distinct ecological communities compared to natural hard substrates, potentially reflecting differences in the materials from which they are constructed. We undertook a metaanalysis of 46 studies to compare the effects of different material types (natural or eco-friendly vs. artificial) on the colonising biota on built structures. Neither the abundance nor richness of colonists displayed consistent patterns of difference between artificial and natural substrates or between eco-friendly and standard concrete. Instead, there were differences in the abundance of organisms (but not richness) between artificial and natural materials, that varied according to material type and by functional group. When compared to biogenic materials and rock, polymer and metal supported significantly lower abundances of total benthic species (in studies assessing sessile and mobile species together), sessile invertebrates and corals (in studies assessing these groups individually). In contrast, non-indigenous species were significantly more abundant on wood than metal. Concrete supported greater abundances of the general community, including habitat-forming species, compared to wood. Our results suggest that the ecological requirements of the biological community, alongside economic, logistic and engineering factors should be considered in material selection for multifunctional marine structures that deliver both engineering and ecological (enhanced abundance and diversity) benefits.
\end{abstract}

\section{Introduction}

Urbanisation of coasts, and the growing blue economy, have led to the proliferation of artificial structures in marine environments (Dafforn et al., 2015; Firth et al., 2016). These structures frequently destroy and fragment natural habitats (Bishop et al., 2017), but also provide novel surfaces for colonisation by marine organisms (Mayer-Pinto et al., 2017). Already, marine-built structures have modified an estimated 1.0-3.4 million $\mathrm{km}^{2}$ of the seafloor (Bugnot et al., 2021) - an area greater than that occupied by the world's seagrass beds and mangrove forests combined (Bugnot et al., 2021). Compared to their closest natural analogue, rocky shores, the surfaces of artificial structures support distinct macrobiotic assemblages (Browne and Chapman, 2011; Bulleri, 2005), often exhibiting lower native diversity and higher numbers of non-indigenous species (NIS) (Airoldi et al., 2015; Connell, 2001). This may reflect differences in construction materials, as well as differences in their topographic complexity and environmental settings (Bulleri and Chapman, 2010; Strain et al., 2018).

The materials from which artificial structures are built commonly differ from natural substrates in their chemical composition, colour, and physical properties such as porosity and microtexture (Bulleri and Chapman, 2010; Loke and Todd, 2016). Concrete, for example, leaches

\footnotetext{
* Corresponding author.

E-mail address: kate.dodds@mq.edu.au (K.C. Dodds).

1 Shared first authors.
} 
metals into the surrounding water column (McManus et al., 2018), has a higher $\mathrm{pH}$ than seawater (Perkol-Finkel and Sella, 2014), and is typically brighter and more homogeneous in microtexture $(<1 \mathrm{~mm}$ scale) than natural rock or wood (Coombes et al., 2015). These material properties play an integral role in the substrate selection and post-settlement mortality of settling microorganisms (Fletcher and Callow, 1992; Tan et al., 2015), with potential effects on the development of macrobiotic communities (Hadfield, 2011; Wieczorek and Todd, 1998).

Most benthic marine invertebrates produce planktonic larvae that disperse over great distances before settling on suitable substrates (Crisp, 1985). Larvae display species-specific responses to chemical and physical cues that confer a high probability of survival and successful reproduction. For example, many invertebrate larvae are negatively phototactic, settling into the darker protective microhabitats of crevices and depressions (Dobretsov et al., 2013; James and Underwood, 1994). Additionally, larvae often respond positively to conspecific chemical cues (Tamburri et al., 2008). Material properties can also influence the survival of organisms post-settlement. Microtextures can provide structure for physical anchoring of biota, or protection from hydrodynamic forces, predation, and/or, desiccation stress (Lim et al., 2020). In the intertidal, the brightness and specific heat content of materials can influence the growth and survivorship of species by affecting the rate and extent to which settled organisms are heated/cooled (Coombes and Naylor, 2012; Raimondi, 1988).

Effects of material types on marine colonisation have been studied for many years, initially to inform the development of antifouling technologies (Cao et al., 2011). More recently, studies have focused on manipulating material composition and surface chemistry (Dennis et al., 2018; Natanzi et al., 2021; Perkol-Finkel and Sella, 2014) to develop multifunctional structures that benefit both humans and nature (Dafforn et al., 2015). Irrespective of their aim, most studies have focused on contrasting pairs or small subsets of materials at one or few locations (Chase et al., 2016; Norris, 1991). Despite the growing number of these individual studies, we know of no attempts to broadly synthesize their results through meta-analyses. Consequently, our capacity to generalise about the effects of material type on species colonisation remains limited.

The effects of material type may vary according to the species pool and identity of available colonists, their functional group, and the time frame over which effects on recruitment are assessed. Effects of material type are expected to be greater for sessile species which settle directly onto the substrate than for mobile species or transient predators such as fish that do not directly interact with the primary substrate (Dobretsov et al., 2013; Sedano et al., 2020). Responses to substrate may vary among functional groups according to their different environmental requirements and sensitivity to environmental stressors. NIS which overcome barriers of antifouling technologies to become established in new locations may be 'selected' for resistance to metals and other stressors (Piola et al., 2009), resulting in differentiated substrate use compared to native species. Identifying settlement patterns on materials could help to understand which types benefit native species, whilst deterring proliferation of NIS (Dafforn, 2017). The effects of materials are expected to weaken with time, as bare substrate becomes rare or even absent, and new colonists instead interact with the secondary substrate provided by space dominants and habitat-forming species (Bruno et al., 2003; Hanlon et al., 2018). Consequently, assessing the effects of material type on the abundance of habitat-forming species is particularly important.

Here we undertook the first systematic review and meta-analysis of the effect of surface material type on the abundance and richness of colonists. The engineering performance of the materials was not assessed. Using experimental studies in a meta-analytic framework, we assessed how recruitment of marine species varies between (1) naturally occurring (e.g., rock, wood): and artificial (e.g., concrete, plastic) materials; and (2) between concrete of standard and eco-friendly (e.g., pHreduced or enhanced with natural materials) composition. We expected natural materials to support a greater richness and abundance (cover or density) of species than artificial substrates overall, but that within these groupings, there would be marked variation in ecological metrics among material types attributable to different material properties. Among artificial substrates, we expected that eco-friendly concrete would support a greater richness and abundance of species than standard concrete. Overall, we expected effects of material type to be greater for sessile species than other groups and weaken through time. In contrast, we predicted that NIS would show a greater affinity for artificial materials.

\section{Methods}

\subsection{Literature search}

We systematically searched for peer-reviewed papers or reports, published between 1984 and 2020, that compared recruitment of marine organisms between natural (groupings: rock, wood, biogenic) and artificial (groupings: clay, concrete, metal, polymer) materials or between a control concrete and an eco-friendly concrete (modified control concrete) (Table S1). Material groupings were based on similarities in properties of individual materials (Table S1). Here, eco-friendly concrete included mixes with the specific goal of enhancing ecological recruitment through the addition of natural materials (hereafter 'additives') or by reducing the $\mathrm{pH}$ of the concrete, and excluded concrete mixes only aimed at reducing the carbon footprint of the mix. The control concrete and concrete in the artificial material grouping 'concrete' included various Portland cement mixes.

First, we searched for relevant studies in Web of Science using keywords associated with artificial marine structures and marine communities (Data S1). The search (initial search: 2017, by ES, PB, AK, and SPF, checked and last updated April 9, 2021 by KD and NS) returned 5461 results. Second, we searched Google Scholar using the same keywords but omitted species origin and functional group keywords and marine* was used instead (completed April 9, 2021 by KD and NS). The search was terminated after ten pages (100 returns) as no additional relevant publications were found. Relevant publications and theses known to the authors but not returned in the search were also included. The title and abstract of each study were initially screened for relevance to our research question (Figure S1). The remaining subset of studies was then assessed for eligibility, including only those that contrasted the richness and/or abundance (density or cover) of colonists between materials of the same age and topographic complexity, resulting in 46 suitable publications (Figure S1; Table S2, S3). These were assigned to one or more of four datasets. Three datasets comprised papers comparing ecological recruitment onto natural and artificial materials of 1) general communities, 2) individual habitat-forming species, and 3) species nonindigenous to the study region (NIS). Habitat-forming species were defined as those whose physical structure (e.g., shells, tests) provides habitat to other species and included barnacles, bivalves, canopy-algae, coral, coralline algae, and tube-forming organisms. The fourth dataset comprised studies comparing the effects of standard and 'eco-friendly' concrete on marine communities.

\subsection{Data extraction}

From each publication, we (ES, PB, AK, SP-F, KD, and NS) extracted the mean and standard deviation (SD) abundance (density and cover combined) and/or richness of species per substrate, the number of replicates, and experiment duration. If a publication reported multiple community metrics (i.e., abundance and richness), species, sites and/or time points, we recorded each comparison as a separate data point. Raw data or clarification was requested from authors where necessary. Where necessary, data were mined from plots using GetData Graph Digitizer (version 2.26.0.20). Where SDs were not available (general community: 126 of 813 data points; habitat formers: 43 of 332; NIS: 31 of 582; eco-friendly: 68 of 136), SDs were imputed based on the fitted 
relationship between $\log$ (mean) and $\log (\mathrm{SD})$ for that dataset (after van Rijkom et al., 1998).

\subsection{Data analysis}

For each dataset, effect sizes for each comparison between an artificial (numerator) and a natural (denominator) material (or an ecofriendly concrete numerator and control concrete denominator) were calculated separately for abundance (density or cover) and richness using the natural logarithm of the ratio of means (ln RR; Hedges et al., 1999) with the escalc function from the R package 'metaphor' (Viechtbauer, 2010). Therefore, positive effect sizes denote greater abundances on artificial than on natural materials and on eco-friendly than on control concrete. For studies where artificial materials shared a natural control material (or vice versa), we partitioned the sample size of the shared material evenly among the shared comparisons (Higgins et al., 2019). A dummy value (0.5) was added to all means and SDs prior to the calculation of effect sizes to avoid taking natural logarithms of zero. In instances where an individual experiment provided multiple data points, we corrected for the resulting correlated sampling (error) variance (Noble et al., 2017) using variance-covariance matrices with a correlation coefficient of 0.5 . Where studies collected data on individual species, we corrected for correlations that may arise due to evolutionary history and shared ecology (Lynch, 1991) by including taxonomic (species) and phylogenetic relatedness (a correlation matrix) as random factors in the analysis (Cinar et al., 2020). In addition, we included the random effects of the parameter (for density and cover only), study ID, experiment ID, and an individual effect size identifier (unique per data row to estimate residual heterogeneity) to account of any other sources of variation.

A multi-level meta-analytic model, including random effects, determined the overall mean effect size between natural and artificial materials (or eco-friendly and control concrete). Due to moderate to high levels of heterogeneity $\left(\mathrm{I}^{2}>60 \%\right.$ ) (Higgins et al., 2003) in the effect sizes, the model was re-run with the following hypothesis-based moderators: interaction between natural and artificial material (or treatment only for eco-friendly concrete); duration (continuous variable); and functional group (benthic, sessile, sessile invertebrates, algae, fish) by material interaction (separately for natural and artificial materials, where possible) (see Data S2 for group details). A three-way interaction between artificial material type, natural material type and functional group could not be investigated due to insufficient data. Individual moderator terms were only tested when interactions were non-significant. Moderator sub-levels were only included in the analysis if they comprised at least three experiments. In this meta-analysis, different locations and separate deployment dates within a publication were considered separate 'experiments'.

Marginal $\mathrm{R}^{2}$ was used to quantify how much heterogeneity was explained by individual moderators and all moderators combined (Moatt et al., 2016; Nakagawa and Schielzeth, 2013). In all models, 'optim' was used as an optimizer (as per Nelder and Mead, 1965). We visualized results using orchard plots (orchaRd package; (Nakagawa et al., 2021b). Pairwise contrasts between moderator sublevels were conducted using general linear hypotheses via the function 'glht' in the 'multcomp' package (Hothorn et al., 2008). To assess whether our results were affected by publication bias, we visually inspected funnel plots of simple (no moderators) and multilevel (with significant moderators) models for asymmetry (Nakagawa and Santos, 2012) and ran Eggers regressions on the same models (Nakagawa et al., 2021a). In no instance was asymmetry detected (Figures S3 and S4; Table S4). Similarly, non-significant intercepts for the models with publication year as a moderator demonstrated that our data were unaffected by time lag bias (Nakagawa and Santos, 2012) (Table S5).

\section{Results}

The overall effect sizes for the four datasets examining differences in abundance or richness of colonists between natural and artificial material types (or eco-friendly and concrete) did not significantly differ from zero (Table 1, Figure S5). Instead, for each analysis, we found moderate to high levels of heterogeneity $\left(\mathrm{I}^{2}>60 \%\right)$ (Table 1$)$. The inclusion of moderators in the models identified key sources of variability in abundance measures for the general community, NIS, and habitatforming species data sets, but not for the species richness data sets nor the abundance of species on eco-friendly vs control concrete (Table S5).

For the general community and the habitat-forming species, we found a significant interaction between artificial and natural materials (Table S5). Natural biogenic materials and wood supported significantly higher (by 21-65\%) abundances of both of these groups than metal and/ or polymer, while wood supported significantly lower abundances (by 32-70\%) than concrete (Figs. 1 and 2, S6 and S7 Tables S6 and S7). When considering richness data, although overall variability in effect sizes was not explained by the addition of moderators, species richness was significantly higher (by 20\%) on wood compared to metal (Table S5 and S7). In addition, the richness of sessile organisms was significantly lower (by 23\%) on metal than natural materials (Table S7). All other pairwise differences between material types were not significant (Tables S7).

For the general community and habitat-forming species, the artificial material by functional group interaction was also significant (Table S5). Sessile invertebrates, benthic species, habitat-forming barnacles, bivalves and corals were significantly less abundant (by 35-89\%) on metal and/or polymer than on any natural material or concrete (Figs. 1 and 3 and S7; Tables S6 and S7). In contrast, neither the interaction between functional groups and natural materials, nor study duration significantly contributed to variability (Table S5). Nevertheless, benthic species were significantly more abundant (46\%) on wood, and sessile invertebrates were significantly more abundant (30\%) on biogenic substrates compared to artificial materials (Tables S5 and S7).

For the abundances of NIS, there was a significant interaction between artificial and natural materials (Table S5). NIS abundances were significantly higher (87\%) on polymers and concrete compared to wood, but had significantly lower (82\%) abundances on metal than wood (Figs. 1 and 4, Tables S6 and S7). This was likely driven by the mixed polymer group within polymers and aluminium within metals (Data S3). All other pairwise differences among material types were not significant (Tables S6 and S7) .

\section{Discussion}

Our study provides the first global quantitative assessment on the influence of material type on the recruitment of marine organisms. Our results show that material type significantly affects abundances of the general community, habitat-forming species, and NIS, but not richness of the general community, suggesting material type should be a key consideration in the design and construction of multifunctional marine structures.

\subsection{Artificial versus natural substrates}

Given the wide variation in material properties and large model heterogeneity, it is perhaps unsurprising that we did not find any overarching effect of natural versus artificial materials on colonist abundance and richness. Instead, we found that colonisation on artificial materials was more variable than on natural materials. This result may reflect the greater evolutionary history of native colonists with natural materials and perhaps differences in the toxic leachates that characterise artificial and natural materials (Bejgarn et al., 2015).

In general, concrete supported greater abundances of species than other artificial substrates and supported similar abundances to natural 
Table 1

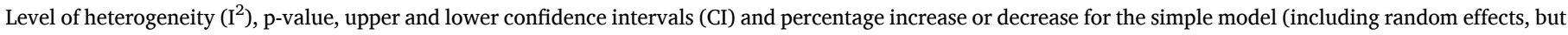
no moderators) for each dataset.

\begin{tabular}{|c|c|c|c|c|c|c|}
\hline Analysis & Estimate & Mean \% increase/decrease on artificial & Lower CI & Upper CI & $p$-value & $\mathrm{I}^{2}$ \\
\hline General community (Abundance) & -0.07 & -6.82 & -0.21 & 0.07 & 0.31 & 99.03 \\
\hline General community (Richness) & 0.02 & -1.68 & -0.13 & 0.09 & 0.76 & 66.76 \\
\hline Habitat-forming species (Abundance) & -0.03 & -3.06 & -0.30 & 0.24 & 0.82 & 99.60 \\
\hline NIS (Abundance) & 0.15 & 15.98 & -0.17 & 0.47 & 0.36 & 74.59 \\
\hline Eco-friendly (Abundance) & 0.04 & 4.54 & -0.29 & 0.38 & 0.80 & 62.37 \\
\hline
\end{tabular}

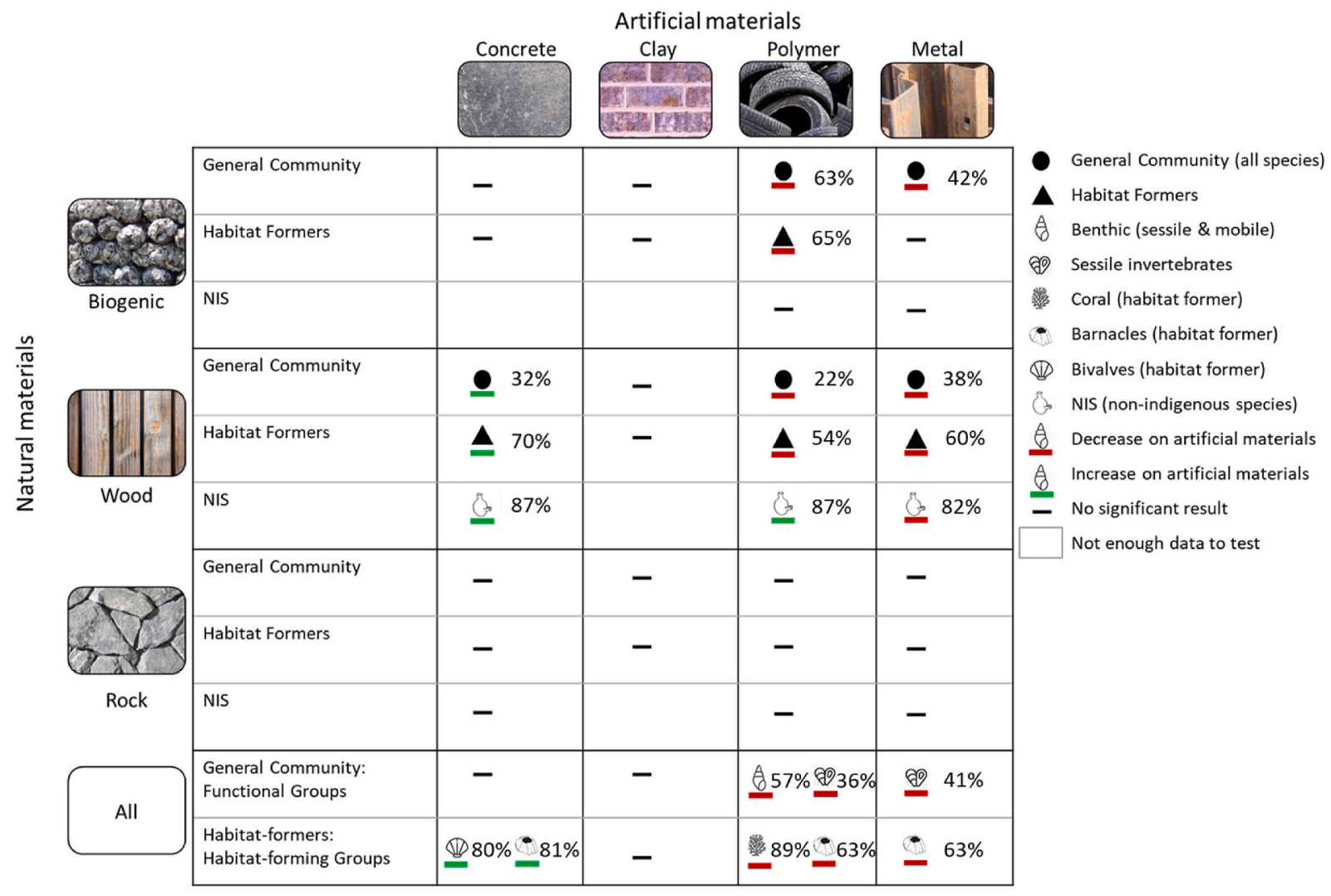

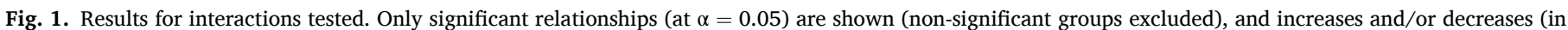

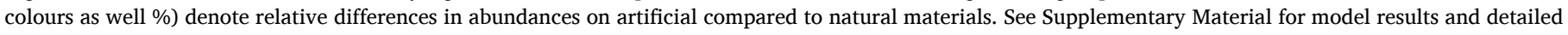
breakdown of groups.

materials. This pattern was particularly strong for sessile invertebrates, including corals, bivalves and barnacles. Concrete, like shell and some rock types, leaches calcium hydroxide into the water, which can act as a settlement cue for calcifying organisms, particularly bivalves and barnacles (Anderson, 1996; Mos et al., 2019). Additionally, concrete typically has a greater surface roughness and porosity than metal or polymer (especially PVC) (Chase et al., 2016), which may positively influence organism adhesion and survival.

Metal and polymer generally supported lower abundances of species than clay, concrete or the natural material categories, wood and biogenic. However, algae and NIS were generally more abundant on polymer than wood. Polymeric materials are often hydrophobic, having a low wettability (Encinas et al., 2010), which can reduce the settlement of some, though not all biota (Callow and Fletcher, 1994; Rittschof and Costlow, 1989). Species, such as some algae and invertebrates, that are still able to settle on low wettability materials, may benefit from reduced competition for space on these surfaces (Rittschof and Costlow, 1989). The comparatively low number of NIS on wood was unexpected as many NIS species are highly successful on wood, having initially been introduced on wooden ship's hulls (Ojaveer et al., 2018). Relatively low abundance on metals was expected as many metals are generally toxic to marine species, though some NIS have evolved tolerance through exposure to metallic anti-fouling agents (Johnston et al., 2017; Piola et al., 2009). Nevertheless, in this study NIS were less abundant on metal than other artificial materials.

Species richness did not significantly vary among material types, irrespective of whether they were natural or artificial. This may be because richness does not consider differences in the identity of species between treatments so is insensitive to species turnover that occurs independent of the number of species present. In addition, many of the studies were relatively short (median duration 4.5 months), such that communities were dominated by few opportunistic or pioneering species (Hanlon et al., 2018; Murray and Littler, 1978) that may be out-competed and in some instances replaced with more species-rich communities over longer time periods.

\subsection{Eco-friendly concrete}

Despite records of increased density and diversity of colonising species on eco-friendly materials (Dennis et al., 2018; Perkol-Finkel and Sella, 2014), we found no significant difference in abundance of the settling community between control and eco-friendly concretes. In situ, 


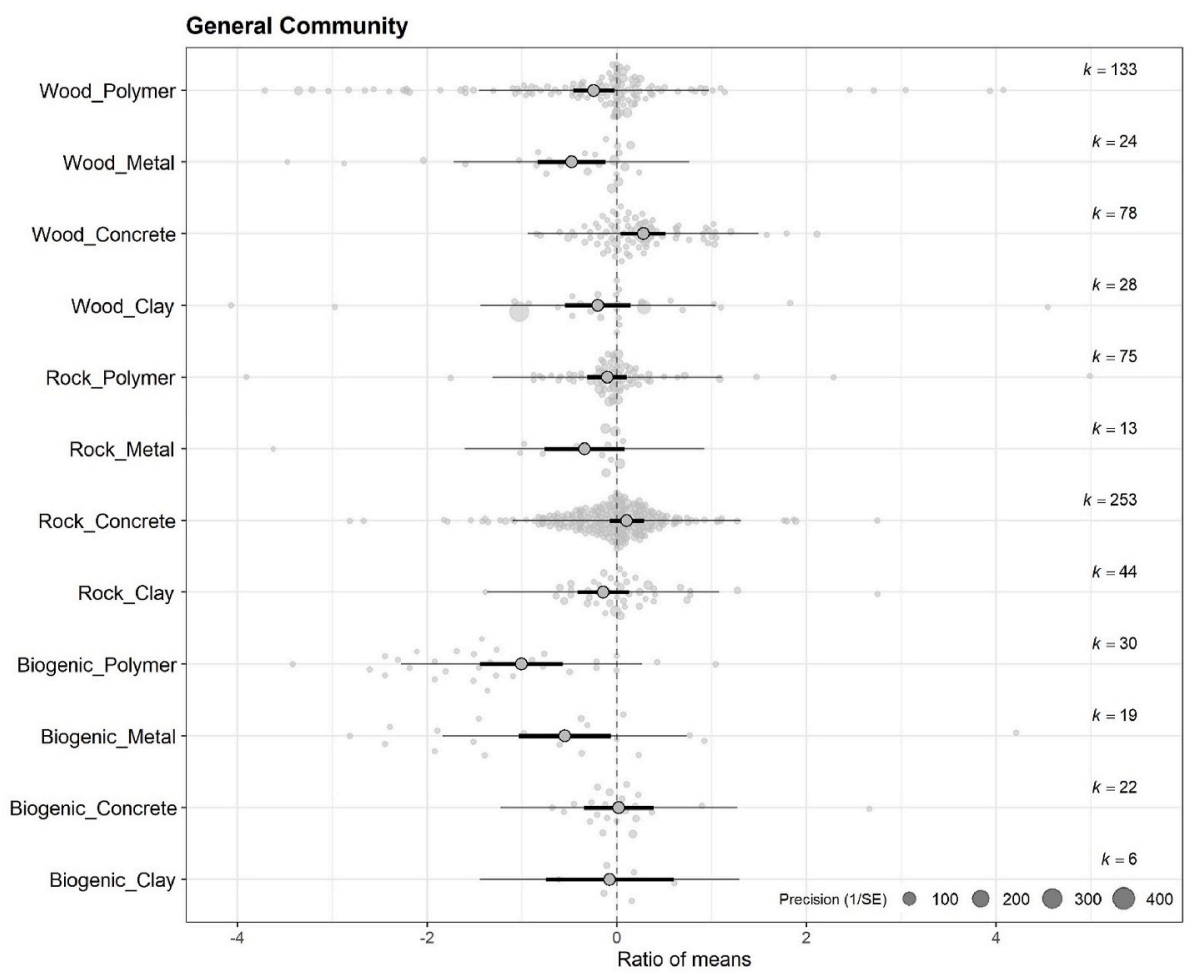

Fig. 2. Orchard plot showing the mean effect size (bordered circle), 95\% confidence interval (bold line) and 95\% prediction interval (fine line) for measures of abundance (cover and density) on different natural and artificial material combinations for the general community. Positive effect sizes denote greater abundances on artificial than natural materials. "K" represents the number of data points.

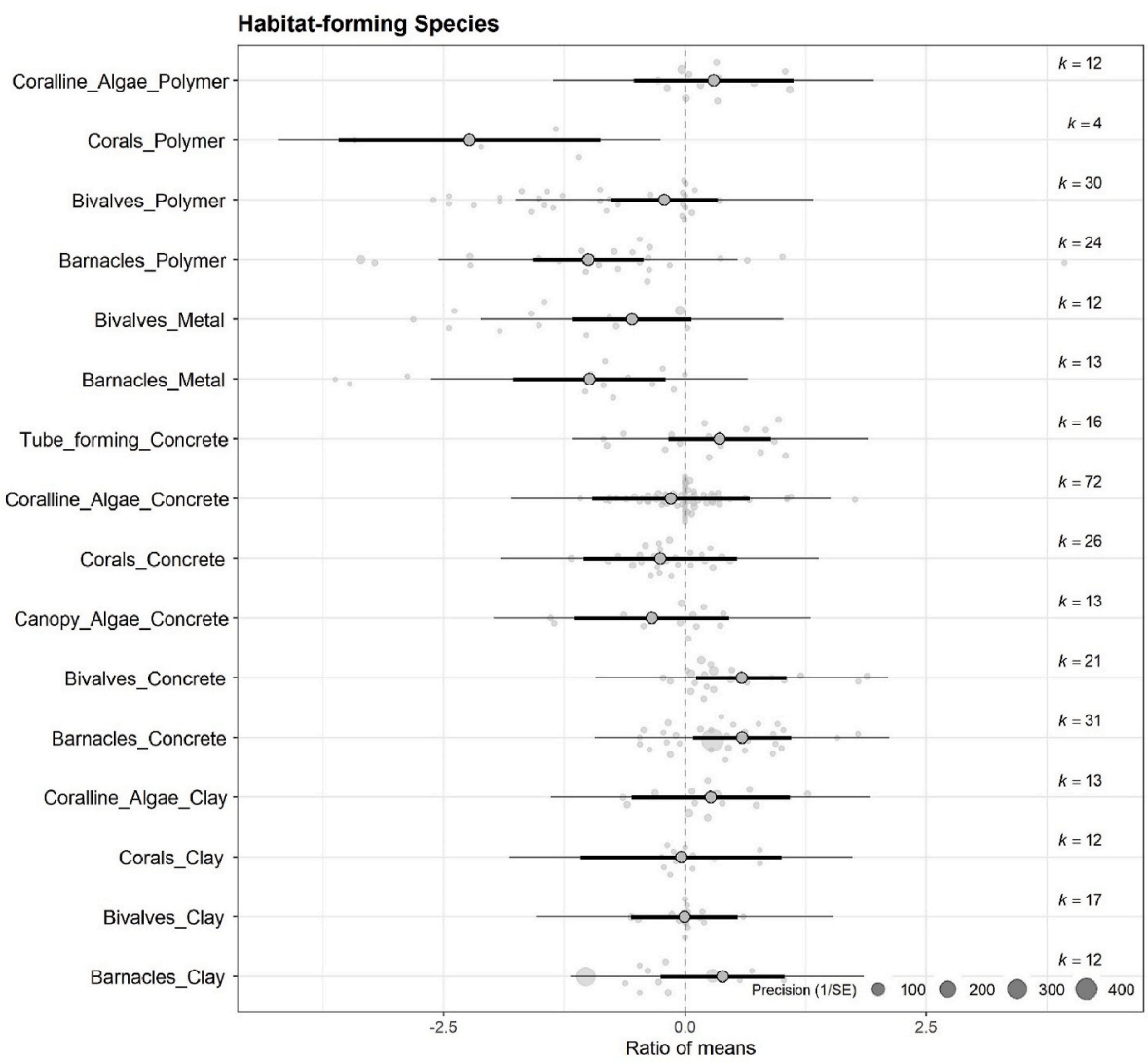

Fig. 3. Orchard plot showing the mean effect size (bordered circle), $95 \%$ confidence interval (bold line) and $95 \%$ prediction interval (fine line) for measures of abundance (cover and density) of different habitat-forming groups on different artificial materials for the habitat-forming species. Positive effect sizes denote greater abundances on artificial than natural materials. "K" represents the number of data points. 


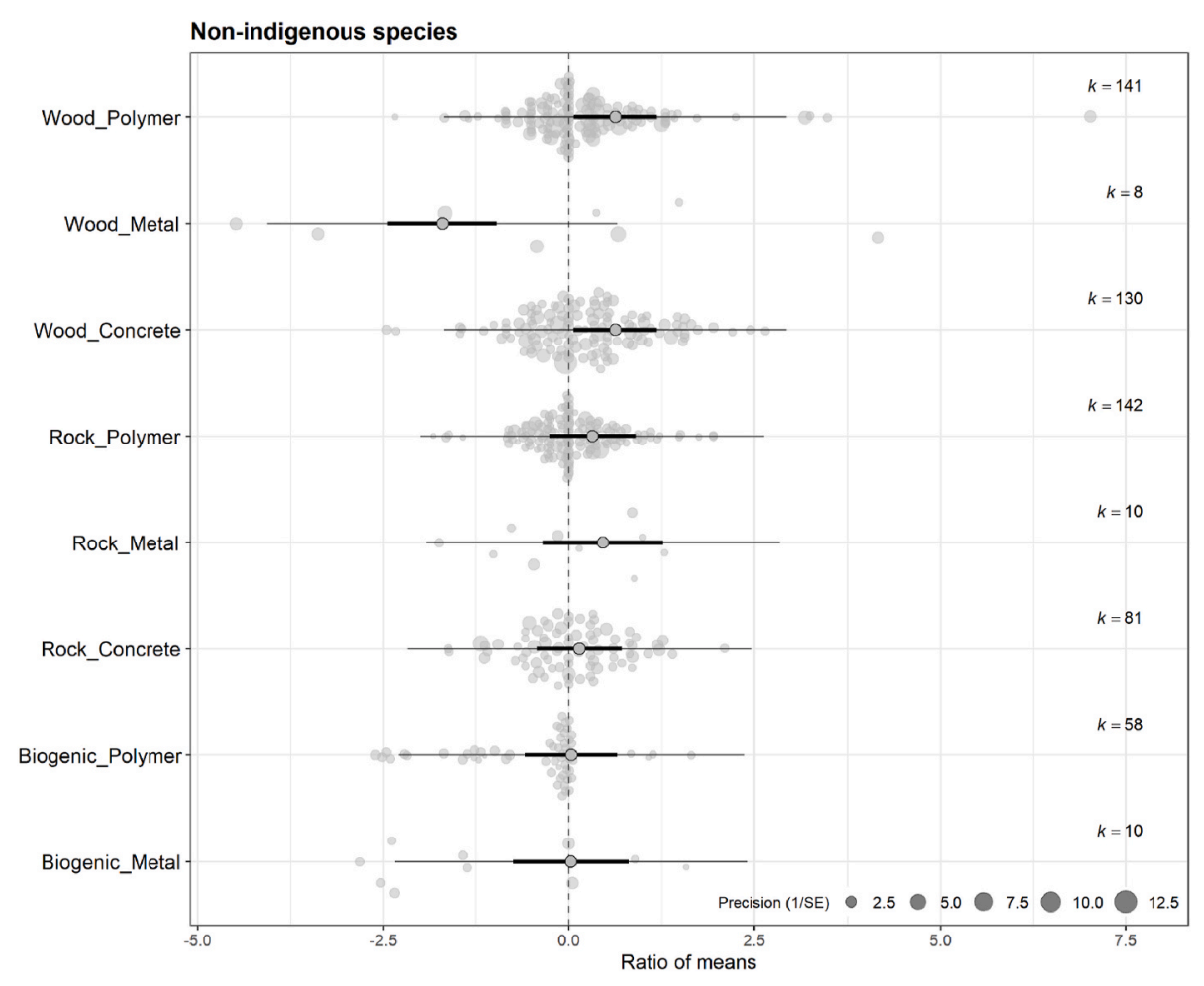

Fig. 4. Orchard plot showing the mean effect size (bordered circle), $95 \%$ confidence interval (bold line) and 95\% prediction interval (fine line) for measures of abundance (cover and density) on different natural and artificial material combinations for non-indigenous species Positive effect sizes denote greater abundances on artificial than natural materials. " $\mathrm{K}$ " represents the number of data points.

the constant flushing of substrate surfaces may dilute concrete leachates into the surrounding water column, diminishing the effect of reduced $\mathrm{pH}$ (McManus et al., 2018; Schaefer et al., 2020). Indeed, studies tracking changes in concrete chemistry through time found that after 3-6 months in a marine environment, the $\mathrm{pH}$ of standard concrete did not differ from the surrounding sea-water (Dooley et al., 1999). Insufficiently high concentrations of natural additives may also have limited the effectiveness of eco-friendly concrete mixes. Two studies tested the effects of different concentrations of additives (coral rubble), and both found increased settlement with increasing concentration (Lee et al., 2009; Neo et al., 2009). Therefore, it is possible that higher concentrations of natural additives within the cement matrix or changes to the fabrication process that allow for higher concentrations near the surface might have a greater influence on recruitment than reducing the $\mathrm{pH}$. Our finding of negligible differences between eco-friendly and control concrete is consistent with Potet et al. (2021) who found alterations to the surface complexity of concrete had greater ecological effect than alterations to the concrete's chemistry. Additionally, the failure of our analysis to find any effect of concrete mixes on recruitment may reflect differential responses of species to these manipulations. Positive effects of concrete on recruitment of calcifying organisms, such as oysters (Anderson, 1996; Mos et al., 2019) may offset negative effects on other species such as non-calcifying algae (Guilbeau et al., 2003), though impacting overall ecosystem functioning. Multivariate analyses that consider the richness and abundance of the community of colonists and species identity may provide greater resolution of effects.

\subsection{Effects of functional group and study duration}

Despite our expectation that sessile species would respond more strongly to material type than mobile species or fish, we found little support for this hypothesis. 'Polymer' was the only material type to elicit a differential response among functional groups. Although it is possible that this result reflected strong habitat and trophic dependencies between sessile and mobile species, it likely also reflected the limited data with which to test the hypothesis. The abundances of mobile species were rarely reported independently of sessile species, necessitating that contrasts were between assemblages combining mobile and sessile counts ('benthic') versus those with sessile species alone. Furthermore, few studies included here documented the effects of material type on fish. Nevertheless, where contrasts were possible, fish were not affected by material type. Additional studies that directly test responses of functional groups to material type are needed to better test this hypothesis.

Additionally, we found no significant effect of study duration on effect size. This was despite our expectation that effects would weaken due to the decreasing amount of primary substrate available for the settlement and growth of new colonists (Dayton, 1971). Studies were, however, generally short and most experiments only considered a single time point. A weak non-significant trend of decreasing effect size over time suggests that if more studies of longer duration and multiple time points were available, a significant effect might be seen.

\subsection{Future work and implications for management}

The results of this study indicate that material types vary markedly in the ecological communities they support. Consequently, in addition to complexity (Strain et al., 2018), material type should be a key ecological consideration when designing artificial structures for humans and nature. Although artificial materials such as metal and polymer supported reduced abundances of species, concrete, the most common material from which artificial structures are constructed (Alexander and Nganga, 2016; Bugnot et al., 2021), supported similar abundances and species richness to natural materials. Consequently, where it is not possible to use natural materials, concrete may be the best artificial material alternative from an ecological perspective. With most of the analysed studies being relatively short term, additional studies that track community development at multiple stages over longer periods of time 
(greater than nine months, the 75th percentile of general community duration data) are, however, needed to confirm the long-term ecological implications of material type. Amongst the species that responded most strongly to material type were habitat-forming marine invertebrates such as corals, bivalves and barnacles, which where they persist and form habitat, often have large positive influences on biodiversity.

A number of physico-chemical properties of materials, such as surface chemistry (e.g., $\mathrm{pH}$, wettability) and micro-texture (e.g., surface roughness), can influence colonisation of organisms to substrates (Wieczorek and Todd, 1998). To optimise different design aspects of eco-engineered materials (e.g., surface chemistry, microtexture), multifactorial manipulative experiments are needed to determine how these properties independently and interactively determine colonisation. These experiments should ideally examine effects on colonisation and population establishment of a range of target and non-target (i.e., NIS) species, under a range of environmental conditions (e.g., high vs low water motion, sunny vs shaded settings), in order to disentangle drivers of variability in results and allow customisation of eco-engineered solutions to site conditions and environmental goals (Evans et al., 2021).

This study considered material performance purely from an ecological perspective. Economic (e.g., cost), logistic (e.g., availability, malleability) and engineering (e.g., durability, strength, corrosivity) factors are also key considerations driving material selection for marine construction (Alexander and Nganga, 2016) and remain to be tested for some of the materials investigated (e.g., biogenic). Increasingly, relative energy and water consumption, greenhouse gas production, and raw material availability also greatly influence material selection (Kappenthuler and Seeger, 2020). Future analyses should consider optimisation of material selection based on ecological, economic, logistic, engineering and sustainability considerations. In instances where ecologically-optimal materials are sub-optimal in other respects it may be possible to apply eco-friendly coatings or panels to the facades of structures to enhance their biodiversity.

\subsection{Conclusion}

The structural properties, price, and availability of construction materials have historically driven material choices for artificial marine structures (Alexander and Nganga, 2016). This study shows that material type affects the abundance of the colonising community, and ecological aspects should be included in material selection criteria. These effects can vary with the functional group and may also vary with environmental conditions such that there is no 'one-size fits all' approach. In general, we show natural materials support greater abundances of marine species than artificial materials, and among artificial materials, concrete supports higher abundances than polymer, metal, and clay.

For the best ecological results, however, site-specific pre-construction surveys evaluating environmental conditions and the identity of potential colonists should be conducted. This, along with structural performance testing and the development of clear environmental goals, will assist in appropriate material selection. Such an approach will be particularly beneficial when combined with other eco-engineering strategies, such as including complexity into the form of structures (Strain et al., 2018).

\section{Author's contribution}

ES and MB designed the study. ES, PB, and AK led the literature search and initial data extraction. KD and NS led data checking and subsequent extraction and performed the analyses under the guidance of SN. KD and NS led the writing, with review and editing by all coauthors.

\section{Data availability statement}

All data is available electronically via Supplementary material.

\section{Declaration of competing interest}

The authors declare that they have no known competing financial interests or personal relationships that could have appeared to influence the work reported in this paper.

\section{Acknowledgements}

Ido Sella for useful comments on earlier drafts. Shimrit Perkol-Finkel and Karen Raubenheimer assisted with the initial literature search and data extraction. Liam Agnew, Maddy Whitton, Lucie Maillet, Albertine Guiton, Jennifer Coughlan and Elisa Biaggi assisted with subsequent data extraction and curation. KD was supported by an iMQRES PhD Scholarship awarded through the Department of Biological Sciences Macquarie University. NS was supported by the Department of Agriculture, Water and Environment's Biosecurity Innovation Program. ES was supported by The Ian Potter Foundation, Harding Miller Foundation, and The New South Wales Government Office of Science and Research. This work was in part financed by the UK Natural Environment Research Council (NERC) INSITE Programme Grant DREAMS (Grant reference NE/T010835/1) awarded to AK.

\section{Appendix A. Supplementary data}

Supplementary data to this article can be found online at https://doi. org/10.1016/j.jenvman.2022.114549.

\section{References}

Airoldi, L., Turon, X., Perkol-Finkel, S., Rius, M., 2015. Corridors for aliens but not for natives: effects of marine urban sprawl at a regional scale. Divers. Distrib. 21, 755-768. https://doi.org/10.1111/ddi.12301.

Alexander, M.G., Nganga, G., 2016. 1 - introduction: Importance of marine concrete structures and durability design. In: Alexander, Mark G. (Ed.), Marine Concrete Structures. Woodhead Publishing, pp. 1-13. https://doi.org/10.1016/B978-0-08100081-6.00001-5.

Anderson, M.J., 1996. A chemical cue induces settlement of sydney rock oysters, Saccostrea commercialis, in the laboratory and in the field. Biol. Bull. 190, 350-358. https://doi.org/10.2307/1543027.

Bejgarn, S., MacLeod, M., Bogdal, C., Breitholtz, M., 2015. Toxicity of leachate from weathering plastics: an exploratory screening study with Nitocra spinipes. Chemosphere 132, 114-119. https://doi.org/10.1016/j.chemosphere.2015.03.010.

Bishop, M.J., Mayer-Pinto, M., Airoldi, L., Firth, L.B., Morris, R.L., Loke, L.H.L., Hawkins, S.J., Naylor, L.A., Coleman, R.A., Chee, S.Y., Dafforn, K.A., 2017. Effects of ocean sprawl on ecological connectivity: impacts and solutions. J. Exp. Mar. Biol. Ecol., Ecological responses to environmental change in marine systems 492, 7-30. https://doi.org/10.1016/j.jembe.2017.01.021.

Browne, M.A., Chapman, M.G., 2011. Ecologically informed engineering reduces loss of intertidal biodiversity on artificial shorelines. Environ. Sci. Technol. 45, 8204-8207. https://doi.org/10.1021/es201924b.

Bruno, J.F., Stachowicz, J.J., Bertness, M.D., 2003. Inclusion of facilitation into ecological theory. Trends Ecol. Evol. 18, 119-125. https://doi.org/10.1016/S01695347(02)00045-9.

Bugnot, A.B., Mayer-Pinto, M., Airoldi, L., Heery, E.C., Johnston, E.L., Critchley, L.P., Strain, E.M.A., Morris, R.L., Loke, L.H.L., Bishop, M.J., Sheehan, E.V., Coleman, R.A., Dafforn, K.A., 2021. Current and projected global extent of marine built structures. Nat. Sustain. 4, 33-41. https://doi.org/10.1038/s41893-020-00595-1.

Bulleri, F., 2005. Role of recruitment in causing differences between intertidal assemblages on seawalls and rocky shores. Mar. Ecol. Prog. Ser. 287, 53-65. https:// doi.org/10.3354/meps287053.

Bulleri, F., Chapman, M.G., 2010. The introduction of coastal infrastructure as a driver of change in marine environments. J. Appl. Ecol. 47, 26-35. https://doi.org/10.1111/ j.1365-2664.2009.01751.x.

Callow, M.E., Fletcher, R.L., 1994. The influence of low surface energy materials on bioadhesion - a review. Int. Biodeterior. Biodegrad. 34, 333-348. https://doi.org/ 10.1016/0964-8305(94)90092-2.

Cao, S., Wang, J., Chen, H., Chen, D., 2011. Progress of marine biofouling and antifouling technologies. Chin. Sci. Bull. 56, 598-612. https://doi.org/10.1007/s11434-0104158-4.

Chase, A.L., Dijkstra, J.A., Harris, L.G., 2016. The influence of substrate material on ascidian larval settlement. Mar. Pollut. Bull. 106, 35-42. https://doi.org/10.1016/j. marpolbul.2016.03.049. 
Cinar, O., Nakagawa, S., Viechtbauer, W., 2020. Phylogenetic Multilevel Meta-Analysis: A Simulation Study on the Importance of Modeling the Phylogeny (Preprint). EcoEvoRxiv. https://doi.org/10.32942/osf.io/su4zv.

Connell, S.D., 2001. Urban structures as marine habitats: an experimental comparison of the composition and abundance of subtidal epibiota among pilings, pontoons and rocky reefs. Mar. Environ. Res. 52, 115-125. https://doi.org/10.1016/S0141-1136 (00)00266-X.

Coombes, M.A., La Marca, E.C., Naylor, L.A., Thompson, R.C., 2015. Getting into the groove: opportunities to enhance the ecological value of hard coastal infrastructure using fine-scale surface textures. Ecol. Eng. 77, 314-323. https://doi.org/10.1016/j. ecoleng.2015.01.032.

Coombes, M.A., Naylor, L.A., 2012. Rock warming and drying under simulated intertidal conditions, part II: weathering and biological influences on evaporative cooling and near-surface micro-climatic conditions as an example of biogeomorphic ecosystem engineering. Earth Surf. Process. Landforms 37, 100-118. https://doi.org/10.1002/ esp. 2232 .

Crisp, D.J., 1985. Recruitment of barnacle larvae from the plankton. Bull. Mar. Sci. 37 $478-486$.

Dafforn, K.A., 2017. Eco-engineering and management strategies for marine infrastructure to reduce establishment and dispersal of non-indigenous species. In: Manag. Biol. Invasions, Proceedings of the 9th International Conference on Marine Bioinvasions (January 2016, Sydney, Australia), vol. 8, pp. 153-161. https://doi. org/10.3391/mbi.2017.8.2.03.

Dafforn, K.A., Glasby, T.M., Airoldi, L., Rivero, N.K., Mayer-Pinto, M., Johnston, E.L., 2015. Marine urbanization: an ecological framework for designing multifunctional artificial structures. Front. Ecol. Environ. 13, 82-90. https://doi.org/10.1890/ 140050.

Dayton, P.K., 1971. Competition, disturbance, and community organization: the provision and subsequent utilization of space in a rocky intertidal community. Ecol. Monogr. 41, 351-389. https://doi.org/10.2307/1948498.

Dennis, H.D., Evans, A.J., Banner, A.J., Moore, P.J., 2018. Reefcrete: reducing the environmental footprint of concretes for eco-engineering marine structures. Ecol. Eng. 120, 668-678. https://doi.org/10.1016/j.ecoleng.2017.05.031.

Dobretsov, S., Abed, R.M.M., Voolstra, C.R., 2013. The effect of surface colour on the formation of marine micro and macrofouling communities. Biofouling 29, 617-627. https://doi.org/10.1080/08927014.2013.784279.

Dooley, K.M., Knopf, F.C., Gambrell, R.P., 1999. PH-NEUTRAL CONCRETE FOR ATTACHED MICROALGAE AND ENHANCED CARBON DIOXIDE FIXATION - PHASE I (No. AC26-98FT40411- 01, 778919). https://doi.org/10.2172/778919.

Encinas, N., Pantoja, M., Abenojar, J., Martínez, M.A., 2010. Control of wettability of polymers by surface roughness modification. J. Adhes. Sci. Technol. 24, 1869-1883. https://doi.org/10.1163/016942410X511042.

Evans, A.J., Lawrence, P.J., Natanzi, A.S., Moore, P.J., Davies, A.J., Crowe, T.P., McNally, C., Thompson, B., Dozier, A.E., Brooks, P.R., 2021. Replicating natural topography on marine artificial structures - a novel approach to eco-engineering. Ecol. Eng. 160, 106144. https://doi.org/10.1016/j.ecoleng.2020.106144.

Firth, L.B., Knights, A.M., Bridger, D., Evans, A.J., Mieszkowska, N., Moore, P.J., O'Connor, N.E., Sheehan, E.V., Thompson, R.C., Hawkins, S.J., 2016. Ocean sprawl challenges and opportunities for biodiversity management in a changing world. Oceanogr. Mar. Biol. Annu. Rev. 54, 79.

Fletcher, R.L., Callow, M.E., 1992. The settlement, attachment and establishment of marine algal spores. Br. Phycol. J. 27, 303-329. https://doi.org/10.1080/ 00071619200650281.

Guilbeau, B.P., Harry, F.P., Gambrell, R.P., Knopf, F.C., Dooley, K.M., 2003. Algae attachment on carbonated cements in fresh and brackish waters-preliminary results. Ecol. Eng. 20, 309-319. https://doi.org/10.1016/S0925-8574(03)00026-0.

Hadfield, M.G., 2011. Biofilms and marine invertebrate larvae: what bacteria produce that larvae use to choose settlement sites. Ann. Rev. Mar. Sci 3, 453-470. https:// doi.org/10.1146/annurev-marine-120709-142753.

Hanlon, N., Firth, L.B., Knights, A.M., 2018. Time-dependent effects of orientation, heterogeneity and composition determines benthic biological community recruitment patterns on subtidal artificial structures. Ecol. Eng. 122, 219-228. https://doi.org/10.1016/j.ecoleng.2018.08.013.

Hedges, L.V., Gurevitch, J., Curtis, P.S., 1999. The meta-analysis OF response ratios IN experimental ecology. Ecology 80, 1150-1156. https://doi.org/10.1890/0012-9658 (1999)080[1150:TMAORR]2.0.CO;2.

Cochrane handbook for systematic reviews of interventions. In: Higgins, J.P., Green, S. Thomas, J., Chandler, J., Cumpston, M., Li, T., Page, M., Welch, V. (Eds.), 2019. Cochrane Handbook for Systematic Reviews of Interventions, Cochrane Book Series. John Wiley \& Sons, Ltd, Chichester, UK. https://doi.org/10.1002/9780470712184. fmatter i-xxi.

Higgins, J.P.T., Thompson, S.G., Deeks, J.J., Altman, D.G., 2003. Measuring inconsistency in meta-analyses. BMJ 327, 557-560. https://doi.org/10.1136/ bmj.327.7414.557.

Hothorn, T., Bretz, F., Westfall, P., 2008. Simultaneous inference in general parametric models. Biom. J. 50, 346-363. https://doi.org/10.1002/bimj.200810425.

James, R.J., Underwood, A.J., 1994. Influence of colour of substratum on recruitment of spirorbid tubeworms to different types of intertidal boulders. J. Exp. Mar. Biol. Ecol. $181,105-115$.

Johnston, E.L., Dafforn, K.A., Clark, G.F., Rius, M., Floerl, O., 2017. Anthropogenic activities promoting the establishment and spread of marine non-indigenous species post-arrival. In: Hawkins, S.J., Evans, A.J., Dale, A.C., Firth, L.B., Hughes, D.J., Smith, I.P. (Eds.), Oceanography and Marine Biology: an Annual Review. CRC Press, pp. 389-419.
Kappenthuler, S., Seeger, S., 2020. From resources to research—a framework for identification and prioritization of materials research for sustainable construction. Mater. Today Sustain. 7-8, 100009. https://doi.org/10.1016/j.mtsust.2019.100009.

Lee, C.S., Walford, J., Goh, B.P.L., 2009. Adding coral rubble to substrata enhances settlement of Pocillopora damicornis larvae. Coral Reefs 28, 529-533. https://doi. org/10.1007/s00338-009-0467-y.

Lim, H.S., Fraser, A., Knights, A.M., 2020. Spatial arrangement of biogenic reefs alters boundary layer characteristics to increase risk of microplastic bioaccumulation. Environ. Res. Lett. 15, 064024 https://doi.org/10.1088/1748-9326/ab83ae.

Loke, L.H.L., Todd, P.A., 2016. Structural complexity and component type increase intertidal biodiversity independently of area. Ecology 97, 383-393. https://doi.org/ 10.1890/15-0257.1.

Lynch, M., 1991. Methods for the analysis of comparative data in evolutionary biology. Evolution 45, 1065-1080. https://doi.org/10.1111/j.1558-5646.1991.tb04375.x.

Mayer-Pinto, M., Johnston, E.L., Bugnot, A.B., Glasby, T.M., Airoldi, L., Mitchell, A., Dafforn, K.A., 2017. Building 'blue': an eco-engineering framework for foreshore developments. J. Environ. Manag. 189, 109-114. https://doi.org/10.1016/j. jenvman.2016.12.039.

McManus, R.S., Archibald, N., Comber, S., Knights, A.M., Thompson, R.C., Firth, L.B., 2018. Partial replacement of cement for waste aggregates in concrete coastal and marine infrastructure: a foundation for ecological enhancement? Ecol. Eng. 120, 655-667. https://doi.org/10.1016/j.ecoleng.2017.06.062.

Moatt, J.P., Nakagawa, S., Lagisz, M., Walling, C.A., 2016. The effect of dietary restriction on reproduction: a meta-analytic perspective. BMC Evol. Biol. 16, 199. https://doi.org/10.1186/s12862-016-0768-z.

Mos, B., Dworjanyn, S.A., Mamo, L.T., Kelaher, B.P., 2019. Building global change resilience: concrete has the potential to ameliorate the negative effects of climatedriven ocean change on a newly-settled calcifying invertebrate. Sci. Total Environ. 646, 1349-1358. https://doi.org/10.1016/j.scitotenv.2018.07.379.

Murray, S.N., Littler, M.M., 1978. Patterns of algal succession in a perturbated marine intertidal Community1. J. Phycol. 14, 506-512. https://doi.org/10.1111/j.15298817.1978.tb02477.x.

Nakagawa, S., Lagisz, M., Jennions, M.D., Koricheva, J., Noble, D.W.A., Parker, T., H, Sanchez-Tojar, A., Yang, Y., O’Dea, R.E., 2021a. Methods for Testing Publicationbiasin Ecological and Evolutionary Meta-Analyses.

Nakagawa, S., Lagisz, M., O’Dea, R.E., Rutkowska, J., Yang, Y., Noble, D.W.A., Senior, A. M., 2021b. The orchard plot: cultivating a forest plot for use in ecology, evolution, and beyond. Res. Synth. Methods 12, 4-12. https://doi.org/10.1002/jrsm.1424.

Nakagawa, S., Santos, E.S.A., 2012. Methodological issues and advances in biological meta-analysis. Evol. Ecol. 26, 1253-1274. https://doi.org/10.1007/s10682-0129555-5.

Nakagawa, S., Schielzeth, H., 2013. A general and simple method for obtaining R2 from generalized linear mixed-effects models. Methods Ecol. Evol. 4, 133-142. https:// doi.org/10.1111/j.2041-210x.2012.00261.x.

Natanzi, A.S., Thompson, B.J., Brooks, P.R., Crowe, T.P., McNally, C., 2021. Influence of concrete properties on the initial biological colonisation of marine artificial structures. Ecol. Eng. 159, 106104. https://doi.org/10.1016/j. ecoleng.2020.106104.

Nelder, J.A., Mead, R., 1965. A simplex method for function minimization. Comput. J. 7, 308-313. https://doi.org/10.1093/comjnl/7.4.308.

Neo, M.L., Todd, P.A., Teo, S.L.-M., Chou, L.M., 2009. Can artificial substrates enriched with crustose coralline algae enhance larval settlement and recruitment in the fluted giant clam (Tridacna squamosa)? Hydrobiologia 625, 83-90. https://doi.org/ 10.1007/s10750-008-9698-0.

Noble, D.W.A., Lagisz, M., O'dea, R.E., Nakagawa, S., 2017. Nonindependence and sensitivity analyses in ecological and evolutionary meta-analyses. Mol. Ecol. 26 2410-2425. https://doi.org/10.1111/mec.14031.

Norris, D.R., 1991. Recruitment, growth, and survivorship of Balanus eburneus with respect to settlement, surface and season. J. Elisha Mitchell Sci. Soc. 107, 123-130.

Ojaveer, H., Galil, B.S., Carlton, J.T., Alleway, H., Goulletquer, P., Lehtiniemi, M., Marchini, A., Miller, W., Occhipinti-Ambrogi, A., Peharda, M., Ruiz, G.M., Williams, S.L., Zaiko, A., 2018. Historical baselines in marine bioinvasions: implications for policy and management. PLoS One 13, e0202383. https://doi.org/ 10.1371/journal.pone.0202383.

Perkol-Finkel, S., Sella, I., 2014. Ecologically active concrete for coastal and marine infrastructure: innovative matrices and designs. In: From Sea to Shore? Meeting the Challenges of the Sea, Conference Proceedings. ICE Publishing, pp. 1139-1149. https://doi.org/10.1680/fsts.59757.124.

Piola, R.F., Dafforn, K.A., Johnston, E.L., 2009. The influence of antifouling practices on marine invasions. Biofouling 25, 633-644. https://doi.org/10.1080/ 08927010903063065.

Potet, M., Fabien, A., Chaudemanche, S., Sebaibi, N., Guillet, T., Gachelin, S., Cochet, H., Boutouil, M., Pouvreau, S., 2021. Which concrete substrate suits you? Ostrea edulis larval preferences and implications for shellfish restoration in Europe. Ecol. Eng. 162, 106159. https://doi.org/10.1016/j.ecoleng.2021.106159.

Raimondi, P.T., 1988. Rock type affects settlement, recruitment, and zonation of the barnacle Chthamalus anisopoma Pilsbury. J. Exp. Mar. Biol. Ecol. 123, 253-267. https://doi.org/10.1016/0022-0981(88)90046-9.

Rittschof, D., Costlow, J.D., 1989. Bryozoan and barnacle settlement in relation to initial surface wettability: a comparison of laboratory and field studies. Sci. Mar. Barc

Schaefer, N., Bishop, M.J., Bugnot, A., Foster-Thrope, C., Herbert, B., Hoey, A., MayerPinto, M., Sherman, C., Vozzo, M.L., Dafforn, K.A., 2020. Ecological Engineering of Marine Infrastructure for Biosecurity. Report prepared for Department of Agriculture, Water and Environment.

Sedano, F., Navarro-Barranco, C., Guerra-García, J.M., Espinosa, F., 2020. From sessile to vagile: understanding the importance of epifauna to assess the environmental 
impacts of coastal defence structures. Estuar. Coast Shelf Sci. 235, 106616. https:// doi.org/10.1016/j.ecss.2020.106616.

Strain, E.M.A., Olabarria, C., Mayer-Pinto, M., Cumbo, V., Morris, R.L., Bugnot, A.B., Dafforn, K.A., Heery, E., Firth, L.B., Brooks, P.R., Bishop, M.J., 2018. Ecoengineering urban infrastructure for marine and coastal biodiversity: which interventions have the greatest ecological benefit? J. Appl. Ecol. 55, 426-441. https://doi.org/10.1111/1365-2664.12961.

Tamburri, M.N., Luckenbach, M.W., Breitburg, D.L., Bonniwell, S.M., 2008. Settlement of Crassostrea ariakensis larvae: effects of substrate, biofilms, sediment and adult chemical cues. J. Shellfish Res. 27, 601-608. https://doi.org/10.2983/0730-8000 (2008)27[601:SOCALE].
Tan, E.L.-Y., Mayer-Pinto, M., Johnston, E.L., Dafforn, K.A., 2015. Differences in intertidal microbial assemblages on urban structures and natural rocky reef. Front. Microbiol. 6 https://doi.org/10.3389/fmicb.2015.01276.

van Rijkom, H.M., Truin, G.J., van 't Hof, M.A., 1998. A meta-analysis of clinical studies on the caries-inhibiting effect of fluoride gel treatment. Caries Res. 32, 83-92. https://doi.org/10.1159/000016436.

Viechtbauer, W., 2010. Conducting meta-analyses in R with the metafor package. J. Stat. Software 36, 1-48. https://doi.org/10.18637/jss.v036.i03.

Wieczorek, S.K., Todd, C.D., 1998. Inhibition and facilitation of settlement of epifaunal marine invertebrate larvae by microbial biofilm cues. Biofouling 12, 81-118. https://doi.org/10.1080/08927019809378348. 